\title{
El esplendor de la belleza
}

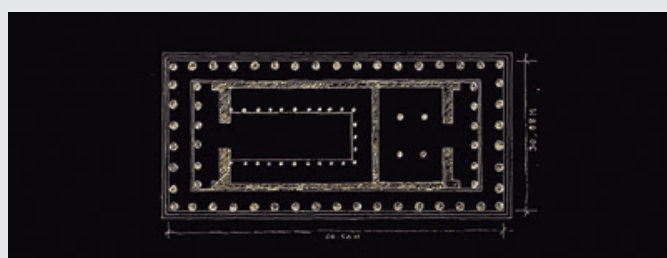

\section{Estructuras vistas, ocultas e ilusorias}

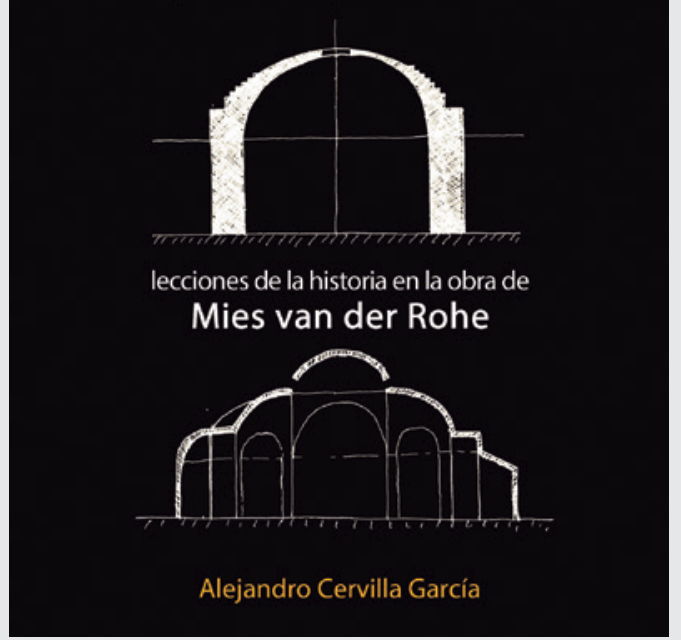

"ESTRUCTURAS VISTAS, OCULTAS E ILUSORIAS". Alejandro Cervilla García ISBN: 9789874160003

Buenos Aires: Diseño, 2017

\begin{abstract}
A lejandro Cervilla es un arquitecto que construye Acolabora con Alberto Campo Baeza, su maestro y mentor. Sin pertenecer estrictamente al ámbito académico, ha desarrollado una sosegada investigación doctoral mediante la cual, sin embargo, no ha querido alejarse de él. El resultado de esta labor ha sido una tesis de reciente lectura, dirigida por Alberto Campo Baeza y Alberto Morell, cuyas palabras prologan este libro en que ahora se transforma. Tesis y libro plasman la meditada mirada de este joven arquitecto a la obra Ludwig Mies van der Rohe; aunque el título elegido para el libro lo oculta.
\end{abstract}

Tomar la obra de Mies como objeto de una investigación doctoral tiene sus riesgos. Harto complejo es no repetir lugares comunes (y sin embargo, también es reciente la revisión de la biografía del maestro alemán por Schulze); no obstante, en los últimos años son varias las investigaciones centradas en el maestro y su arquitectura. Con su tesis, presentada en el Departamento de Proyectos Arquitectónicos de la Escuela de Arquitectura de Madrid, Alejandro ha abordado la tarea de reencontrarse con este hito y mito de la arquitectura moderna.
¿Qué hace particular la mirada a la obra de Mies van der Rohe ofrecida aquí? Pues, deliberado o no, desmontar el mito de la belleza como expresión de la verdad estructural (también insistía en ello Ramón Serrano Avilés en su reciente tesis doctoral, aún inédita).

Ya se sabe que a los grandes, por aquello del mito, se les atribuyen intenciones y razones que ayudan a hacerlos memorables. Una de las asociadas a la obra de Mies es la de que, en ella, la belleza surge de la sinceridad estructural. Dicho de otra manera, aquello tan referido sobre la presunta tesis agustiniana de la belleza como esplendor de la verdad -splendor veritas-, que a Mies le rondase en la cabeza, según parece, a través de la lectura de Romano Guardini (iay, San Agustín!).

Consciente quizás de que el maestro alemán no era tan fiel seguidor de la presunta máxima agustiniana, Alejandro Cervilla aborda una pormenorizada mirada a su obra desde el punto de vista estructural. Con paciencia de incrédulo, repasa los edificios de Mies y descubre en ellos tres maneras de disponer la estructura: vista, oculta e ilusoria. Si se quedase ahí, la cuestión no dejaría de ser una taxonomía académica, pero ya se ha dicho que la visión ofrecida en este libro (y en la tesis doctoral del que procede) es algo más que eso; no en vano se ha apuntado que el autor no pertenece al ámbito académico.

Consciente del terreno peliagudo en que se mueve su investigación, Alejandro convierte en "universal" su clasificación de las estructuras empleadas por Mies van der Rohe. Para ello repasa escogidamente la historia de la arquitectura en busca de edificios con estos mismos usos. Bien es verdad que el repaso es parcial e interesado; sin embargo, cumple su cometido. En ello se muestra además un gesto interesante del autor: la experiencia personal de la arquitectura analizada. $Y$ es que, ha dedicado no poco de su tiempo libre a visitar, analizar y estudiar todos los edificios que emplea como casos particulares (quizás por ello haya tardado tanto en ver la luz su tesis doctoral).

El hábil recurso al estudio de los casos singulares de la arquitectura del pasado: el Partenón o el Panteón; Santa Sofía o la Sainte Chapelle; el Palacio de Carlos V o los palacios nazaríes de la Alhambra; es un refuerzo de la óptica desde la que se mira la obra del maestro alemán. Con ello se sostiene la tesis de que, en arquitectura, casi nunca nada es lo que parece: ni siquiera al invocar el paradigma de la sinceridad constructiva.

A veces, recuerda el autor, la estructura se oculta en los edificios en favor de la expresión del espacio. Otras, la estructura finge ser lo que no es para confundir a los sentidos. Otras incluso, la estructura se deja vista para dar cuenta de cómo los pesos se distribuyen en el aire y se llevan hasta el suelo. Estos recursos históricos se descubren en la obra de Mies: ocultar, enseñar y sugerir (o confundir), siempre con un fin superior: la razón de la belleza.

Para demostrar al lector que la estructura ha sido un elemento expresivo, aparecen en el texto los cálculos que Alejandro hace de las estructuras de edificios históricos; también, de las obras de Mies van der Rohe, como si no se fiase de aquella máxima del esplendor de la verdad como génesis de la belleza en ellas. Y lo que se demuestra con este ejercicio, tedioso y quizás innecesario, es que, hasta en los casos de pretendida sinceridad, la componente expresiva gana al presunto esplendor de la verdad. iEsas cosas!

Así que, la belleza en arquitectura resplandece por sí misma. Y es que, de ser esplendor de algo, la belleza solo parece ser esplendor de la belleza; y lo de serlo de la verdad sea solo tal vez cuestión moral, lo dijese Platón, San Agustín, Santo Tomás o San Anselmo de Canterbury (sobre ello cabe atender a la arqueología de esta idea expuesta por Tatarkiewich); eso da igual ahora. $\dot{\mathrm{O}}$ es acaso menos bello el Crown Hall cuya estructura finge ser lo que no es? ¿̇Es menos bello el pilar cruciforme del Pabellón de Barcelona por no ser todo lo eficaz que sería con iguales perfiles y distinta geometría? ¿Y la casa Farnsworth con sus planos horizontales flotantes y sus pilares orientados al revés de lo que la óptima forma de transmitir las cargas de unos elementos a otros dicta? iQué bello esplendor!, sí; pero no de la verdad, ide la mentira!, sí, de la mentira.

El último capítulo del libro se dedica a "las columnas de Mies" como elementos expresivos. Con las correlaciones históricas correspondientes, el autor descubre hasta cien tipos de columnas en la obra de Mies van der Rohe. De ellas, entresaca algunos ejemplos paradigmáticos: la del Pabellón de Barcelona, las de la Casa Tugendhat, la de la Gallería de Arte de Berlín, la de la casa Farnsworth o la famosísima esquina del Alumni Memorial Hall del IIT, donde Mies recuerda a Palladio más que nunca. Y todo ello para insistir en lo mismo: que en la obra del gran maestro alemán, la estructura es más poética que veraz; y que eso no le resta un ápice de belleza.

Repasar la obra de Mies a la luz de la expresión estructural es lo novedoso de este libro. La comparación con la arquitectura del pasado y el cálculo de los elementos estructurales son solo apoyos a la tesis principal: la importancia en arquitectura de una bella percepción. ¿̇Qué es el pilar cruciforme tan caro a Mies, sino una pertinaz contradicción por mor de la belleza? Así que, lo que queda claro al terminar el libro es que la sinceridad estructural es solo un mito. Porque, como se deduce de lo dicho por Alejandro Cervilla, la belleza solo es esplendor de la belleza; lo demás es poesía. 